\title{
Experimental study and mathematical simulation of the mixed convection in a rectangular area with a local heat source and the heat sink at the external boundaries
}

\author{
Vyacheslav I. Maksimov and Dmitriy A. Nagornov \\ Institute of Power Engineering, Tomsk Polytechnic University, Tomsk 634050, Russia
}

\begin{abstract}
The results of the experimental determination of temperatures and numerical simulation of temperature fields in a mixed convection in a rectangular area with a heatconducting walls at a local energy source on the bottom are presented. For the experimental determination of temperature fields in a mixed convection method of thermocouple measurements was used. Studies were conducted at Reynolds numbers $10 \leq \operatorname{Re} \leq 1500$ and Rayleigh $103 \leq \mathrm{Ra} \leq 105$. For the verification of obtained experimental data mathematical simulation of mixed convection in the region with the use of a software package Comsol Multiphysics is carried out. A good agreement between the results of experimental determination of the local characteristics of mixed convection in a rectangular volume with a local source of energy and heat-conducting walls with theoretical consequences obtained in the simulation of convective flows using a mathematical package is established. It makes it possible to make a conclusion about the possibility of application for the analysis of flow conditions of viscous heat-conducting gas of experimental procedure based on methods of thermocouple measurements. At the same time the developed approach to the experimental study of mixed convection is applicable in a wide enough range of the main flow parameters and the experimental conditions.
\end{abstract}

Analysis of the processes of natural convection in recent years sufficiently intensively conducted within both theoretical [1-3] and experimental [4, 5] studies. The results are obtained, on the basis which it is possible to make important conclusions about basic laws governing this process. The process of the mixed convection in the cavities with the local sources of heat emission $[5,6]$ is considerably less studied. At the same time mixed convection is the sufficiently typical regime of cooling microelectronic equipment, for example [1]. Convection together with thermal conductivity substantially affects the maximum permissible values of heat fluxes in closed domains, and their examination becomes very important for the tasks, in which other methods of heat removal are impossible or ineffective [5].

The purpose of study was the experimental determination of temperatures values and numerical simulation of temperature fields on under the conditions for the mixed convection in rectangular region with a heat-conducting wall and local energy source on the bottom of the cavity.

For experimental studies the experimental installation, a schematic diagram is shown in Fig. 1 was developed. The study area is a hollow parallelepiped with dimensions $0,55 \times 0,40 \times 0,40 \mathrm{~m}$. The glass was used as a wall material. The temperature was measured by chromel-copel thermocouple. Power heat source was set by an electronic power control devices $(0 \div 100 \mathrm{~W})$ by changing the voltage.

This is an Open Access article distributed under the terms of the Creative Commons Attribution License 4.0, which permits unrestricted use, distribution, and reproduction in any medium, provided the original work is properly cited. 


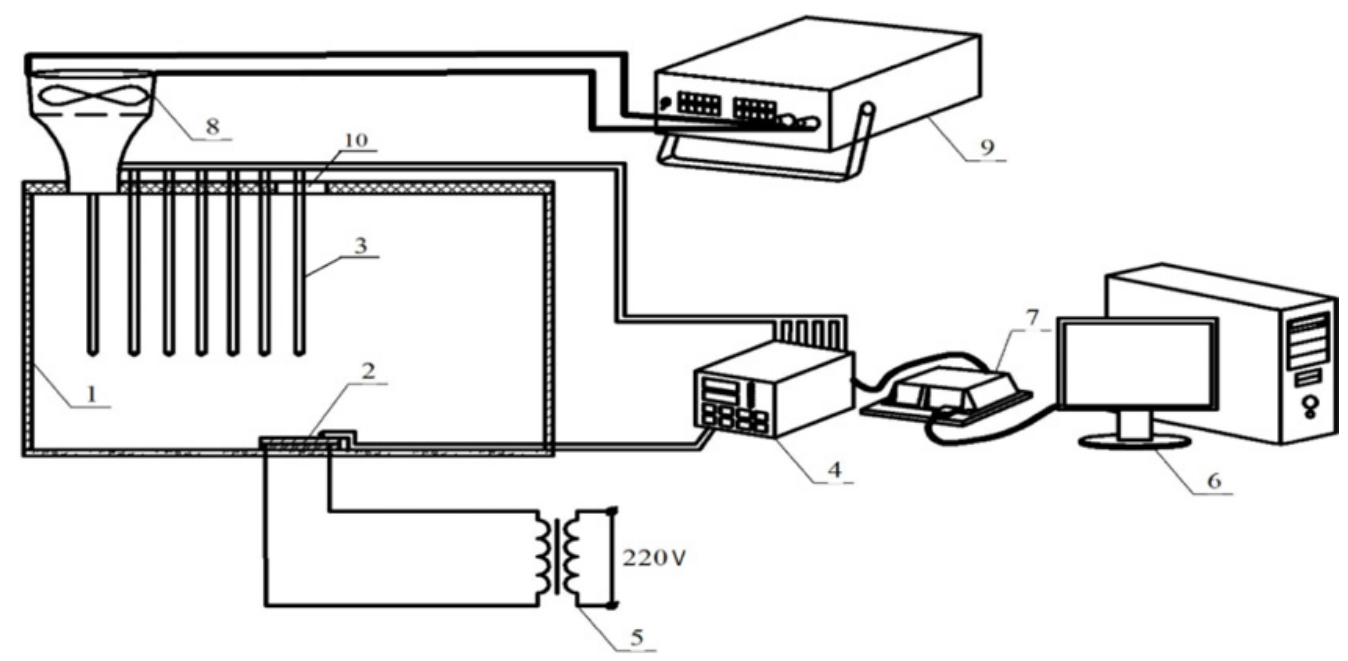

Figure 1. Schematic diagram of the experimental installation: (1) the capacity wall filled with air; (2) the heat source; (3) temperature meters (thermocouple); (4) analog-to-digital converter; (5) autotransformer; (6) personal computer; (7) network adapter; (8) injection installation, located at the entrance to the area; (9) power source, (10) zone of air outlet.

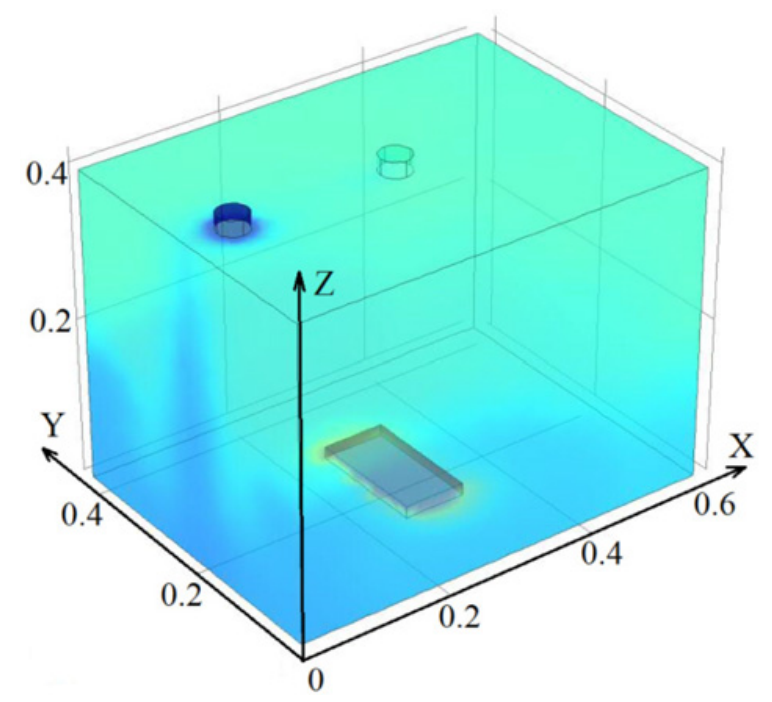

Figure 2. Area of solving the problem.

For organizing the movement of the air mass in the volume axial fan with leveling flow cap was used. Temperature measurements were carried out at different powers of the heat source and axial fan. In the experiments varied the location of thermocouples in the study area. For connection of analog-to-digital converter with the personal computer, the network adapter, which ensures the galvanic isolation between devices was used. As a means of data processing software package NI LabVIEW was used. The values of temperatures were recorded in real time with saving the received data. The total relative systematic error in the determination of temperatures did not exceed $4 \%$ in the whole range of parameters.

Developed approach to an experimental study of temperature fields under the conditions for the mixed convection in the cavities with the local source of heating and gas injection differs from the 


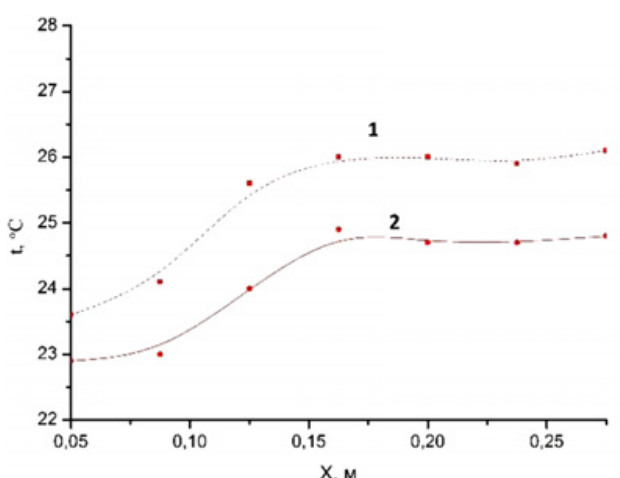

$\mathrm{a}$

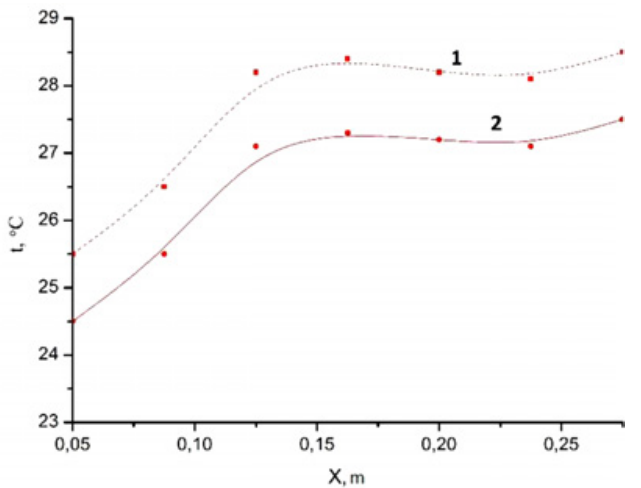

b

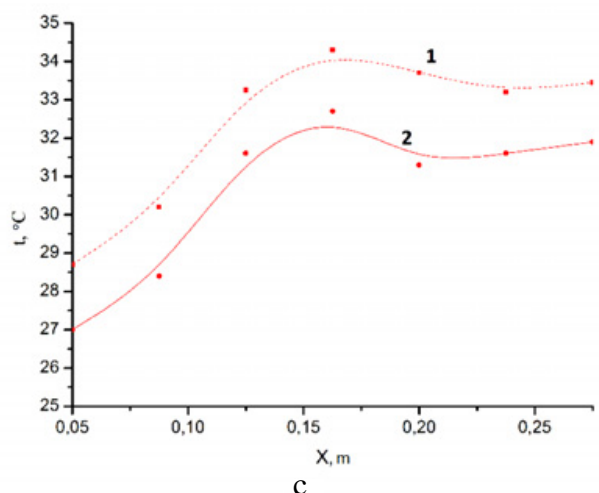

Figure 3. Temperature distribution in the $\mathrm{X}$ in section $\mathrm{Z}=\mathrm{Y}=0.20 \mathrm{~m}$ considered area, with the power source of heat $(\mathrm{a}-2.7 \mathrm{~W}, \mathrm{~b}-11.4 \mathrm{~W},-23.4 \mathrm{~W}): 1$ - the results of mathematical simulation; 2 - experimental data.

measurement methods used traditionally [6]. Use of thermocouples for measuring the temperature distribution combined with possible errors in the determination of $\mathrm{T}$, caused by the inertia of measuring instruments. Therefore one of the research tasks was the justification for the reliability of measurement results. For this purpose proposed a new variant of verification the experimental results.

Recently the software packets, intended for solving the wide range of tasks fluid and gas dynamics and also heat and mass transfer $[4,8]$ are obtained wide acceptance. It was established that in many instances the results of simulation of convection processes with the application of such packets are reliable therefore in this work the substantiation of the authenticity of the results of experimental studies carried out via comparison with the solution of mixed convection problem by that corresponding to conditions for executed experiments.

For mathematical simulation of mixed convection in considered area (Fig. 2) the software package Comsol Multiphysics was used. When creating a model, module Heat Transfer Module's NonIsothermal Flow was used.

Figure 3 shows typical values of the local temperatures measured as a result of experimental studies and mathematical simulation in section $\mathrm{Z}=0,20 \mathrm{~m} \mathrm{Y}=0,2 \mathrm{~m}$ considered area with different power of heat source. It is seen that the temperature profiles correspond to the conditions for generation of mixed convection flows in this regime. The increase in power heat source (Figs. 3b,c) leads to essential transformation of the temperature distribution over the coordinate of the $\mathrm{X}$ in the considered section and increase temperature on the axis of symmetry and the near-wall region. 
Analysis of distributions of $t$ (Fig. 3) allows conclusing that the thermocouple measurements in the covered range of variation of the Reynolds and Grashof well reflect the real picture of flow. Near the injection zone of cold air temperature is lower than average. Coming nearer to heat source temperature increases and decreases away from it. The higher the intensity of heat source, the more clearly stands local extremum on the curve $t(x)$. It can be concluded that the measured temperature values correctly reflect the physical picture of the process.

Comparison of the results of mathematical simulation with obtained experimental data allows making conclusions about their high degree of conformity. The deviations of theoretical and experimental values $t$ do not exceed 3\% that is plotted not only in the confidence the interval of the random errors but also it does not exceed systematic one. Also it should be noted the acceptable correspondence of the form of experimental and theoretical dependences $t(x)$, this illustrates to the certain degree not only the authenticity of the results of the executed experiments, but also the high quality of the model of the mixed convection, method and algorithm of the solution of the corresponding boundary-value problem, being been the systematic basis of the packet Comsol Multiphysics.

In conclusion, it may be noted that a good agreement between the results of experimental determination of the local characteristics of mixed convection rectangular volume with a local source of energy and heat-conducting walls with theoretical consequences obtained at simulation of convective flows by means of mathematical package, allows concluding the possibility of applying for the analysis of flow regimes of viscous heat gas experimental procedure based on the methods of thermocouple measurements. Developed approach to experimental investigation of mixed convection is applicable to a wide enough range of variation of the basic flow parameters and the experimental conditions.

Work performed under the research state assignment "Science" (Code of Federal Target Scientific and Technical Program 2.1321.2014).

\section{References}

[1] Kuznetsov G.V., Sheremet M.A. New approach to the mathematical simulation of thermal regimes for electronic equipment, Russian Microelectronics. V. 37. No. 2 (2008) 131-138

[2] Kuznetsov G.V., Sheremet M.A. Mathematical modelling of complex heat transfer in a rectangular enclosure, Thermophysics and Aeromechanics. 2009. V. 16. No. 1. P. 119-128

[3] Kuznetsov, G.V., Kurilenko, N.I., Maksimov, V.I., Mamontov, G.Ya., Nagornova, T.A. Heat transfer under heating of a local region of a large production area by gas infrared radiators, Journal of Engineering Physics and Thermophysics, 2013. V. 86. - Issue 3, P. 519-524

[4] Kuznetsov, G.V., Maksimov, V.I., Sheremet, M.A. Natural convection in a closed parallelepiped with a local energy source, Journal of Applied Mechanics and Technical Physics, 2013 V. 54. No. 4. P. 588-595

[5] F. Corvaro, M. Paroncini, M. Sotte PIV and numerical analysis of natural convection in tilted enclosures filled with air and with opposite active walls, International Journal of Heat and Mass Transfer, Volume 55, Issues 23-24, November 2012, Pages 6349-6362

[6] Kaloudis E. Large eddy simulations of turbulent mixed convection in the charging of a rectangular thermal storage tank, International Journal of Heat and Fluid Flow, 2013 V. 44. P. 776-791

[7] S.G. Tajia, G.V. Parishwadb, N.K. Sanea Enhanced performance of horizontal rectangular fin array heat sink using assisting mode of mixed convection, International Journal of Heat and Mass Transfer, 2014 V. 72. P. 250-259

[8] Vladimír Gerlich, Kateřina Sulovská, Martin Zálešák COMSOL Multiphysics validation as simulation software for heat transfer calculation in buildings: Building simulation software validation, Measurement, Volume 46, Issue 6, July 2013, Pages 2003-2012 